\title{
Pasando página: breve historia de la prensa escrita en la India
}

\author{
Alejandra VAL CUBERO \\ Universidad Carlos III de Madrid \\ Alejandra.val@uc3m.es
}

Recibido: 05/10/2010

Aceptado: 15/03/2011

\begin{abstract}
Resumen
La prensa en la India inicia su recorrido cuando el país todavía es colonia británica a finales del siglo XVIII y principios del siglo XIX. La prensa moderna aparece tras la independencia en 1947 pero es a partir de los años ochenta, gracias a las medidas liberalizadoras del gobierno de Rajiv Gandhi cuando tiene su máximo despeje. En la actualidad y al contrario que en la mayoría de los países occidentales, el medio escrito está teniendo un desarrollo importante tanto en el número de lectores como en el de títulos publicados motivado, entre otros factores, por el crecimiento de una clase media letrada deseosa de informarse y consumir noticias que apelen a sus intereses y nuevo estilo de vida.
\end{abstract}

Palabras clave: Prensa, India, desarrollo.

\section{Turning the page: a brief history of newspapers in India}

\begin{abstract}
The press in India began its journey when the country was still a British colony in the late eighteenth and early nineteenth centuries. The modern press appeared after India's independence in 1947 but it's only starting from the eighties, due to the liberalization measures of Rajiv Gandhi's government, that it experienced a strong development. At present and as opposed to what is occurring in Western countries, the written media is witnessing a major development both in the number of readers as well as in the number of newspapers published, especially due to the rise of a literate middle class eager to learn and consume news that appeals to their interests and new lifestyle.
\end{abstract}

Key words: newspapers, India, development.

\section{Referencia normalizada}

VAL CUBERO, Alejandra (2011): "Pasando página: breve historia de la prensa escrita en la India”. Estudios sobre el mensaje periodístico. Vol. 17, núm. 1, págs.: 215-224. Madrid, Servicio de Publicaciones de la Universidad Complutense.

Sumario: 1. Introducción. 2. Los primeros periódicos. 3. La llegada de la independencia y el desarrollo de la prensa escrita. 4. El cambio de siglo. 5. Conclusión. 6. Referencias bibliográficas.

\section{Introducción}

La India está experimentando un gran número de cambios económicos y sociales difíciles de predecir hace décadas. Con más de un billón de habitantes, diecisiete lenguas oficiales y miles de dialectos, éste país del sudeste asiático ha conformado junto con Brasil, Rusia y China lo que se conoce como el grupo BRIC y que lideran las nuevas potencias en desarrollo, dispuestas a tener más poder de decisión en organizaciones internacionales como el Banco Mundial o las Naciones Unidas.

En todo este contexto de transformación tecnológica, la prensa india también está sufriendo ciertas transformaciones con un incremento muy importante -al contrario que en la mayoría de los países occidentales- tanto del número de periódicos y revistas publicadas como del número de lectores. Para analizar brevemente la historia de la prensa en la India, las diferentes etapas que vamos a señalar están 
directamente relacionadas con determinados hechos históricos o económicos: en sus comienzos la prensa india estuvo una íntimamente ligada a la presencia británica, los primeros periódicos, -así como los primeros periodistas- procedían de Gran Bretaña y trabajaban en la Compañía de las Indias, aunque rápidamente la élite india se sirvió de este medio como manera de reivindicación y de protesta ante la presencia extranjera. La segunda etapa comienza tras la independencia con Gran Bretaña en 1947, y supondría el inicio de la prensa moderna y el impulso de una prensa autóctona para el público indio. Las medidas liberalizadoras llevadas a cabo a finales de los ochenta y principios de los noventa de la mano de Rajiv Gandhi hijo de Indira Gandhi- y líder del Partido en el Congreso inaugurarían una tercera etapa; es en este momento cuando surgen ciertos grupos mediáticos y se produce la concentración de los principales periódicos y semanarios en manos de poderosas familias indias, al mismo tiempo que nace una prensa más local que viene impulsada por el apoyo de los partidos políticos regionales, deseosos de contar con diarios que sigan su agenda política. La última etapa nos llevaría al momento actual, con el crecimiento de la clase media india -que algunos analistas cifran en más de trescientos millones de personas- que se ha subido al carro del consumo y de las nuevas tecnologías y están transformando el medio prensa.

\section{Los primeros periódicos}

Uno de los primeros periódicos publicados en la India fue The Bengal Gazette fundado por el irlandés James August Hicky en 1780, bajo el lema de un periódico comercial, abierto a todos los partidos y bajo ninguna influencia externa (Raghavan, 1994: 3) y aunque la pretensión del director era entretener al mismo tiempo que informar, sus editoriales contra las tropas militares británicas y en concreto contra el gobernador Warren Hastings y su mujer, dieron lugar a su cierre definitivo y a la expulsión de Hicky de la India en 1782. El periódico a pesar de su corta duración se hizo famoso por sus viñetas humorísticas y sus comentarios satíricos y se convirtió en el foco de inspiración de un nuevo periodismo indio reivindicativo y crítico que ya se estaba formando en esos momentos (Robin, 2003: 45).

Desde finales del siglo XIX y gracias a la apertura del canal de Suez en 1869, el viaje entre Gran Bretaña y la costa bengalí se redujo drásticamente y el intercambio de personas, objetos e ideas fue más constante y fluido. El inicio de las primeras líneas ferroviarias facilitó la mayor distribución de mercancías e incrementó las relaciones comerciales entre las diferentes regiones, muchas de las cuales vivían en completa autarquía y sin relación con el exterior. La llegada de ciertos avances técnicos relacionados con la impresión y la maquetación también estuvo en la base del desarrollo inicial de la prensa, así como la aparición del sistema de telégrafo, con el nacimiento de la Oriental Telephone Company y de la Anglo-Indian Telephone Company en 1880, que permitió agilizar las conexiones entre las ciudades que ya estaban conectadas por ferrocarril como Bombay, Madrás y Calcuta.

La prensa que surge a mediados del siglo XIX no se diferencia mucho de la prensa pionera de las décadas anteriores y es una prensa elitista dirigida principalmente a los colonos británicos y a la clase culta india, que acogió con 
deleite periódicos como Amrita Bazar. Esta prensa de élite no tenía por lo general una tirada de más de trescientos ejemplares y sufrió serios problemas por la falta de financiación y el control gubernamental a la que estuvo sometida (JEFFREY, 2010: 61). La primera ley contra la libertad de prensa, The Vernacular Press Act de 1878, estuvo liderada por el entonces Viceroy de la India y máximo mandatario británico Lord Lytton quien decretó que todas las publicaciones que no fueran en inglés debían pasar por un registro oficial antes de ser impresas. Lord Lytton trataba de acallar de esta manera los comentarios desfavorables que se estaban gestando con motivo de la segunda guerra anglo-afgana (1876 -1880) y en la que India por ser la colonia más próxima al conflicto, tenía un papel de aliado al lado de los británicos.

Otro de los grupos que se servirían de los medios impresos para difundir sus ideas religiosas fueron los misioneros. La promulgación del Charter Act en 1813 permitió la llegada de nuevos misioneros cristianos sin ningún tipo de restricción y en las congregaciones más importantes, como la de los misioneros del estado de Serampore -al este de la India- se llegaron a publicar hasta tres revistas en varias lenguas: the DigDurshan, una revista mensual en bengalí, the Samachar Durpar, una revista semanal también en bengalí y Friend of India publicado en inglés. A través de sus artículos se trataba de promover las ventajas del cristianismo y el establecimiento del imperio británico en la India, con continuas críticas al hinduismo o budismo consideradas como religiones impías propias de salvajes (RAGHAVAN, 1994: 5).

La principal novedad de la prensa de finales del siglo XIX y principios del siglo XX fue la aparición de publicaciones dirigidas por indios, como es el caso de Somprakash, Sulabh Samachar, Halisahar Patrika, Bharat Mihir, Dacca Prakash, Sadharani y Bharat Sanskarak, entre otras. La mayoría de los periodistas que colaboraron en estas revistas estaban implicados en los incipientes movimientos independentistas que en estos momentos se estaban gestando y eran muy críticos con la presencia colonial, aunque también valoraban ciertas medidas sociales puestas en funcionamiento por los británicos y relativas a la educación. Este fue el caso de Ram Mohan Roy líder del movimiento que se conocería como Brahmo Samaj. Mohan Roy fundó la publicación en inglés The Brahmanical Magazine (1821) especializada en aspectos relacionados con la religión, la publicación en lengua persa Mirat-ul Akhbar (1823) centrada en temas internacionales y que vio la luz con un artículo sobre el hambre el Irlanda, -aliándose de esta manera con el movimiento independentista irlandés- y la revista en lengua bengalí The Sambad Kaumudi (1821) canal de difusión de sus ideas progresistas y en la que se publicaron numerosos ensayos en contra de los matrimonios concertados a temprana edad, la prohibición del sati -por la que la mujer era incinerada junto el cadáver de su marido-. Desde las páginas de los diferentes diarios lideró una campaña a favor de educación femenina que comenzó a tener éxito a mediados del siglo XIX y criticó duramente el sistema de castas. Casi todos los integrantes del Brahmo Samaj colaboraron directa o indirectamente con algún periódico, Roy obtuvo el apoyo financiero y moral de sus amigos Dwarkanath Tagore -abuelo del escritor y Premio Nobel de literatura Rabindranath Tagore- y de James Silk Buckingham, un inglés de ideas liberales y defensor de la causa india. Otros líderes del movimiento como 
Ishwar Chandar Widyasagar dirigió Dwarkanath Vidyabhustan y Kesbab Chandra Sen, Man Mohan Ghosh y Devendranath Tagore escribieron sus artículos en The Indian Mirror, un semanario quincenal fundado en 1861 y que se convertiría una década más tarde en un diario. Rabindranath Tagore fundó el periódico Sadhana en 1890 y Gandhi llevo a cabo desde Sudáfrica el proyecto de un semanario en inglés, tamil y gujarati que llevaría por nombre Indian Opinion.

El gobierno inglés ante el temor de proliferación de periódicos en los diferentes idiomas nativos promulgó The Vernacular Press Act de 1878, y la Newspapers Act en 1908 por las que se instaba a cerrar los periódicos sospechosos de publicar artículos tendenciosos o contrarios a la seguridad de la corona británica. Desde este momento todos los medios indios se convirtieron en posibles conspiradores, más aún tras los altercados que enfrentaron a los británicos y a los indios en 1857. La Compañía Británica de las Indias Orientales para conquistar nuevos territorios había reclutado a soldados indígenas y tras varios incidentes surgió lo que se conoce como la insurrección de los cipayos contra los británicos que desencadenaron numerosos actos de violencia y de rebeldía. Uno de los periódicos más críticos con las actuaciones británicas fue The Hindu fundado por Nawab Humayun Jah Bahadur y William Pillai y que pasaría a ser en uno de los periódicos más leídos en lengua inglesa en el siglo XX.

La importancia de la prensa escrita como medio para hacer circular las ideas independentistas también fue tenida en cuenta por el líder del movimiento independentista pacifista, Mohandas Karamchand Gandhi que no sólo colaboró con diferentes periódicos, sino que supo utilizar a los medios -sobre todo la prensa

My Mouth is Gagged

\section{HЯRIJAI}

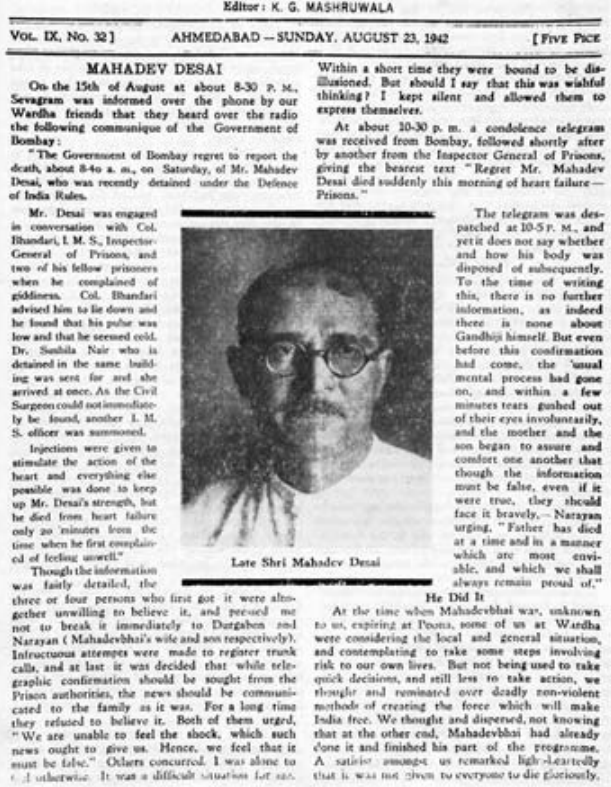

extranjera- para dar a conocer la situación de su país y las movilizaciones que se estaban llevando a cabo. Durante su estancia en Sudáfrica, Gandhi participó en el diario Indian Opinion (1904) que se publicaba en cuatro lenguas: inglés, gujarati, hindi y tamil y a su vuelta a la India dirigió tres periódicos: Navajivan (1919-1931) un semanario escrito en gujarati , Young India (1919-1932) y Harijan (1933-1948) ambas en inglés. Harijan, o hijo de dios, era el nombre con el que Gandhi nombraba a los miembros de las castas más desfavorecidas o los intocables y a través de esta revista abogó por la igualdad de derechos entre todas las castas y el fin de la discriminación por razones de etnia o religión.

Hasta la independencia con Gran Bretaña, los periódicos que más repercusión tuvieron en el movimiento independentista indio fueron The Hindu 
(1878), Malayala Manorama (1889), Aj (1920), Ananda Bazar Patrika (1922), Mathrubhumi (1923), Hindustan Times (1927), Indian Express (1932), Thanthi (1942), Dainik Jagran (1947), Hind Samachar (1948), Prajavani (1948) y Amar Ujala (1948). La mayoría de los cuales solo estuvieron en circulación varios años, con excepciones importantes de The Hindu, Hindustan Times, Indian Express o Malayala Manorama que lograron transformarse y adaptarse a los nuevos públicos y hoy forman parte de los diarios más leídos en el país.

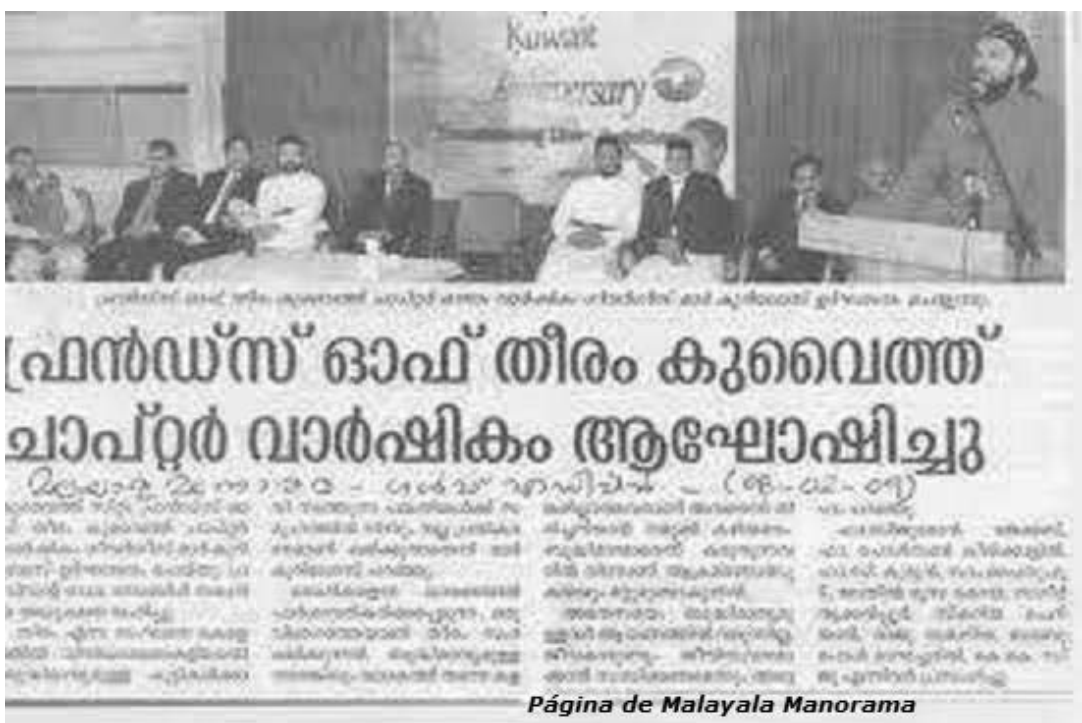

\section{La llegada de la independencia y el desarrollo de la prensa escrita}

La Constitución india aprobada el 26 de enero de 1950 dedicó un apartado especial a la libertad de expresión que fue recogida en el artículo 19 del texto constitucional. El recién elegido Primer Ministro Jawaharlal Nehru y líder del ala moderada socialista del Congreso Nacional Indio destacó "que prefería tener una prensa libre a pesar de los peligros que podía conllevar el mal uso de esa libertad, que una prensa regulada” (NeHRu, 1982: 272). Nehru impulsó la aprobación del Delivery of Books and Newspapers Act en 1954, en el que se obligaba a los editores de libros y periódicos a depositar una copia en la National Library de Calcuta y abogó por recoger los derechos laborales de los periodistas en The Working Journalists and other Newspaper Employees Act de 1955. Durante el gobierno de Nehru y pese a los avances progresistas impulsados por los diferentes ministerios, siguieron siendo constantes las medidas que regulaban la labor de la prensa: The Newspaper Act (1956) reservaba al gobierno la opción de regular el precio de los periódicos dependiendo de su tamaño y del número de páginas y The Defence of India Act (1962) que prohibía la publicación de cualquier tipo de información que pusiera en riesgo la seguridad nacional y las operaciones militares, ley que fue ampliada en el Civil Defence Act de 1968.

El control sobre los medios se hizo más visible tras la muerte de Nehru y la llegada al poder de su hija y sucesora Indira Gandhi. La noche del veinticinco al 
veintiséis de junio de 1975, la Primera Ministra proclamó el Estado de Emergencia con la clausura de cientos de periódicos y semanarios durante los dieciocho meses que duro el asedio. Indira Gandhi también abolió The Press Council of India aprobada en 1966 y que permitía una cierta autonomía editorial y dio órdenes estrictas sobre los temas considerados publicables de los temas no adecuados para su publicación. El fin del Estado de Emergencia, lejos de alejar a los periodistas e inversores del medio escrito trajo consigo el incremento nada desdeñable del número de publicaciones. Entre 1976 y 1979, en tan solo tres años, la circulación de periódicos se incrementó en un cuarenta por ciento en los diarios y un treinta y cuatro por ciento en semanarios, crecimiento que seguiría su escalada en la década posterior y que continúa en la actualidad (JEFFrEy, 2000: 39).

La apertura a los mercados extranjeros, el desarrollo de los medios técnicos y la mejora lenta pero progresiva de la tasa de alfabetización, también impactaron en el crecimiento de la prensa nacional y regional a finales de los años setenta y principios de los ochenta. La utilización de ciertos medios técnicos como la impresión offset que permitió transmitir fotografías de manera más rápida y sencilla y la llegada de los ordenadores y traductores informáticos facilitaron el nacimiento de una prensa escrita en las lenguas minoritarias, proyecto que tuvo el apoyo del Research Institute for Newspaper Development para promover la diversidad y la riqueza lingüística.

La prensa regional también tuvo el apoyo de los partidos políticos regionales deseosos de contar con una prensa más centrada en informaciones que recogieran su ideario. Los anunciantes se dieron cuenta de la importancia de la prensa local para llegar a un público objetivo que no tenía porque conocer el inglés -idioma administrativo- o el hindi -idioma oficial- pero que leía sin dificultad el telugu, el marathi o el urdu. Según las estimaciones de Press in India, el número de periódicos pasó de nueve millones en 1976 a más de cuarenta millones en 1996, y en 1997 el 60\% de la población de hábitat urbano y la cuarta parte de los habitantes de hábitat rural leían prensa local y nacional de manera regular (RAO, 1999: 2).

La creación de grupos mediáticos en manos de poderosas familias fue otro de los grandes cambios de este momento. Un estudio sobre la situación de la prensa a finales de los ochenta estableció que el $72 \%$ de los periódicos en activo estaban en las manos de familias dedicadas a los negocios -principalmente en el sector industrial- y que habían decidido invertir en este sector al ver su espectacular desarrollo (RAJAGOPAL, 2001: 156). The Indian Federation of Working Journalists publicó un pequeño libro titulado India's Monopoly Press: a Mirrow of Distortion en 1973 donde señalaba que la concentración del medio escrito estaba en aumento en toda la India. Entre los nuevos propietarios se encontraba la familia Jain, directora del Times of India, la familia Goenka al frente de Indian Express Newspapers, la familia Kandathil gestora del Malayana Manorama y la familia Chopra, dueña de Hind Samachar, entre otras. La mayoría de estas familias se había enriquecido gracias a la comercialización de materias primas o del textil y quería invertir en los nuevos medios de comunicación. Estas familias, además, no formaban parte de las castas de élite sino de las castas más comerciales, este era el caso del fundador del Indian Express, Rammanth Goenka perteneciente a la casta de 
los Marwari o la familia Kandathil, de origen cristiano o S.P Adithanar, propietario de Dina Thanthi uno de los periódicos más leídos en el Estado de Tamil Nadu y perteneciente a la casta de los nadars, y que creó el periódico en 1977 para apoyar al partido nacionalista de corte socialista Dravida Munnetra Kazhagam (DMK).

\section{El cambio de siglo}

A pesar de que el periódico británico The Econonomist vaticinó en su número de agosto del 2006 que la extinción de los periódicos en países como el Reino Unido era cosa de tiempo, otro parece ser el camino recorrido por la prensa india en este cambio de siglo. La World Association of Newspapers señaló en el año 2009 que la venta de periódicos se había incrementado en un 46\% entre el año 2000 y el 2008 y que los ingresos publicitarios en este medio no dejaban de aumentar. En un contexto en el que muchos periódicos europeos y americanos están cerrando por la crisis económica mundial y la dura competencia de internet, el comercio de periódicos indios asciende a más de noventa millones de copias diarias en sus más de diecisiete lenguas locales. La buena marcha del medio impreso está, sin embargo, ensombrecida por nuevos desafíos a los que se tendrá que hacer frente: por una parte el aumento del coste de producción y de distribución han hecho disminuir el número de páginas; y, por otra, sigue siendo muy difícil acceder a un sector de la población en plena expansión, como es el público joven, que se siente más cercano a otros medios de comunicación como es la televisión e internet.

El reto futuro implicará captar a este sector joven y muy numeroso a través de publicaciones que conecten con sus intereses y preocupaciones, así como dirigirse a los más de trescientos cincuenta millones de personas adultas que se estima serán capaces de leer en la próxima década. Si desde la independencia, el número de letrados en la India ha pasado de cincuenta millones a trescientos millones de lectores potenciales, la labor del gobierno y de los distintos planes nacionales y regionales será impulsar nuevas medidas que sigan este camino. El Estado de Kerala, al sur de la India, cuenta con las tasas de desarrollo educativo más altas de todo el país, con un $90 \%$ de la población que sabe leer y escribir; en el polo opuesto está el Estado de Bihar, al norte de la India y de habla hindi, cuyos índices de alfabetización no llegaban al veinte por ciento en 1960 y siguen siendo los más bajos de todo el país (JEFFREY, 2000: 30).

El avance y crecimiento de la prensa escrita tiene lugar en los Estados con mayores niveles de alfabetización, son los estados más politizados, con gobiernos de izquierdas, y que llevan décadas promoviendo una educación gratuita y pública sin distinción de casta, étnica, clase, religión o género como base de su desarrollo, este es el caso de Kerala, Tamil Nadu y Maharashtra (JefFrey, 2000:32).

En la actualidad, entre los periódicos nacionales con mayor tirada están los publicados en lengua inglesa, The Times of India, The Hindu y Hindustan Times. Estos diarios tienen una historia de más de un siglo y medio y han sido los testigos principales de los cambios que han acontecido en el país. The Times of India hizo su aparición pública en noviembre de 1838 bajo el nombre The Bombay Times and The Journal of Commerce y en 1850 se convirtió en una publicación diaria. El periódico 
estaba especializado en recoger las informaciones que hacían referencia a Europa, América y el subcontinente asiático y después de la independencia pasó a manos indias, abandonando el emblema del unicornio y el león -símbolos del imperio británico- por los dos elefantes que acompañan cada primera página. En la actualidad pertenece a The Times Group, uno de los grandes grupos mediáticos del país, que a su vez es propiedad de la familia Sahu Jain quien dirige otros periódicos como The Economic Times, Mumbai Mirror, el Navbharat Times y el Maharashtra Times, Femina y Filmfare por citar solo algunas de sus principales cabeceras. The Times of India cuenta con más de cinco ediciones, además del inglés y en el año 2007 lanzó desde Bangalore su edición en canarés y en abril del 2008 su edición desde Chennai. The Times of India ha sido elegido uno de los seis mejores periódicos del mundo por la BBC y tiene una circulación diaria de 2.7 millones de copias vendidas según el Audit Bureau of Circulations del año 2009.

Hindustán Time (HT) es el segundo periódico inglés más leído en la India. Fundado en 1924 por Sunder Singh Lyallpuri y Shiromani Akali en el Estado de Punjab y comprometido en el movimiento independentista indio desde sus orígenes, forma parte del HT Media Ltd, un conglomerado de medios en manos de la familia Birla. El periódico tiene más de seis millones y medio de lectores diarios según el Indian Readership Survey del año 2008 y ha estado dirigido durante gran parte de su historia reciente por Shobhana Bhartia, hija de KK Birla. El periódico dejó de publicarse durante 1942 como acto de protesta por las medidas censoras británicas
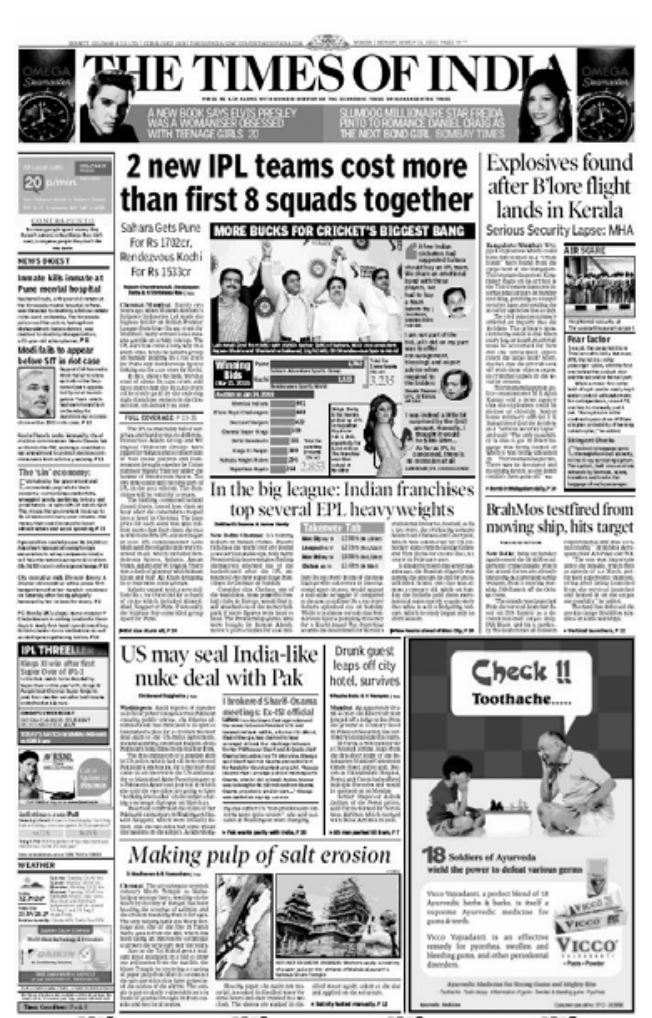
y entre sus colaboradores más directos contó con el apoyo de Mahatma Gandhi y de su hijo, Devdas Gandhi que participó como editor del periódico hasta los años sesenta. En la actualidad tiene ediciones en Delhi, Mumbai, Kolkata, Lucknow, Patna, Ranchi, Bhopal y Chandigard.

El tercer diario más leído en lengua inglesa es The Hindu (Indian Readership Survey, 2008). El periódico se publica en catorce ciudades indias: Bangalore, Chennai, Coimbatore, Delhi, Hubli, Hyderabad, Kochi, Kolkata, Madurai, Mangalore, Thiruvananthapuram, Tiruchirapalli, Vijayawada y Visakhapatnam y en 1995 fue el primero que lanzó su edición online. The Hindu nació en septiembre de 1878 de la mano del reformista indio y profesor G. Subramania Aiyer y aunque al principio pareció tener un posicionamiento neutral, rápidamente se perfiló como una medio crítico con el gobierno británico, 

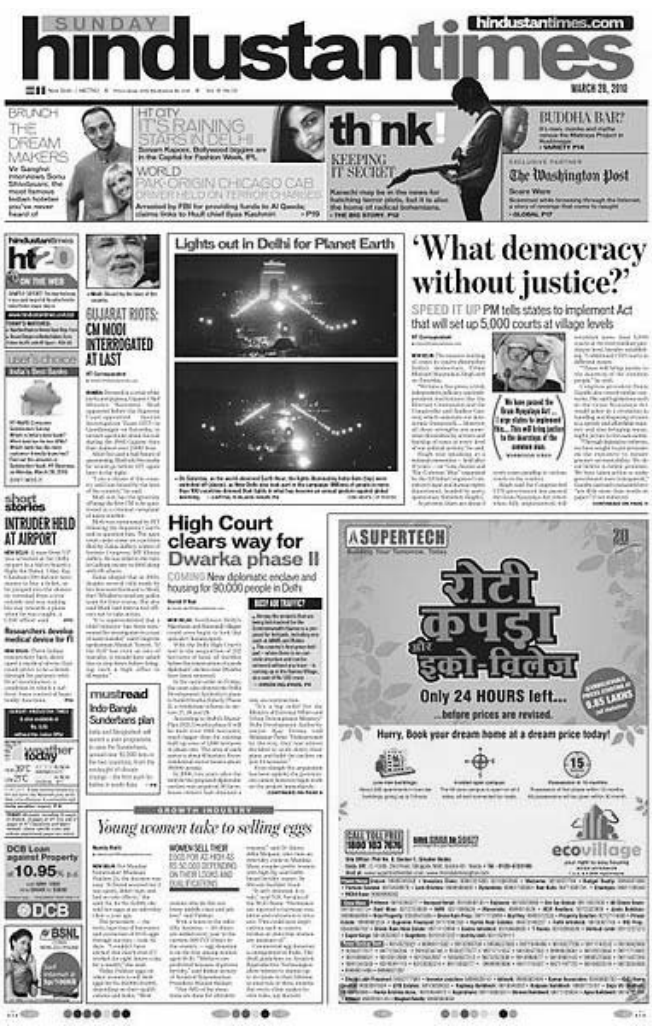

Primeras páginas de The Times of India, Hindustan Times y The Hindu

alcanzando una mayor presencia tras su participación en la sesión anual del Indian National Congress en 1887. En sus comienzos The Hindu se publicaba cada miércoles e introdujo el color en 1940. De tendencia progresista, pertenece en la actualidad a la familia Kasturi y ha estado dirigido por G. Kasturi de 1965 a 1991, N. Ravi de 1991 a 2003, y su hermano N. Ram, a partir de 2003.

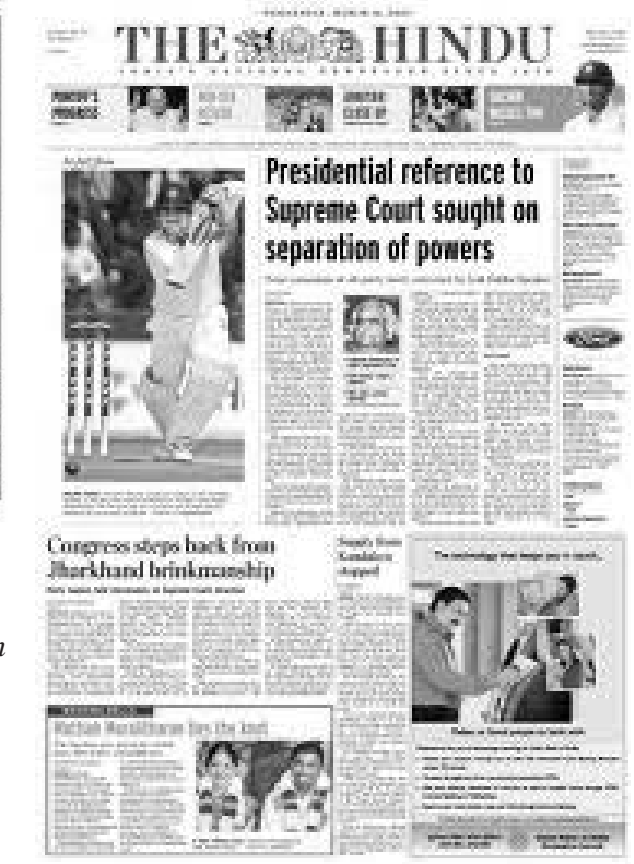

\section{Conclusión}

La prensa ha sido muy importante en su papel de reconfiguración de la India como nación tras la independencia en 1947. Los medios de comunicación llegaron a la India relativamente tarde, la radio se introdujo en 1924 y la televisión en 1959, perfilándose como medios al servicio del partido en el poder y sin competencia externa hasta comienzos de los años noventa, cuando las leyes impulsadas por Ravij Gandhi permitieron la llegada de nuevos medios de comunicación que alterarían todo el panorama mediático en el país.

En la actualidad, este país del sudeste asiático cuenta con el mayor número de periódicos del planeta, desbancando a China y a Estados Unidos. Son más de 62.000 los periódicos publicados y veinte de los cien diarios del mundo con mayor tirada son de titularidad india. El espectacular desarrollo del país viene de la mano de la clase media india -con más de trescientos millones de potenciales consumidores- así 
como una élite muy bien formada que está haciendo de muchos enclaves, como la ciudad de Bangalore, la cuna del desarrollo tecnológico y científico actual. Parece que la evolución seguirá su curso en los próximos años, el Banco Central Indio, ha estimado su crecimiento para el año 2010-2011en un 8,8\%, superando a la Unión Europea (1,7\%) y a EEUU (2, 7\%) (Banco Central Indio, 2009).

A pesar de la diversificación y de la aparición de la prensa local, los periódicos en hindi y de tirada nacional son los que gozan de mayor circulación, seguidos de los publicados en inglés, y la prensa no ha sufrido -como sí lo está sufriendo la televisión, el cine o la publicidad- los efectos del hinglish, una mezcla de hindi y de inglés que ha dado lugar al nacimiento de una lengua simplificada, de vocabulario reducido, sencilla de pronunciar y destinada sobre todo a la comunicación oral y que ha entrado de lleno desde mediados de los noventa en los medios audiovisuales.

El país que se define a sí mismo como la democracia más grande del planeta cuenta con el apoyo inestimable de los periódicos y los periodistas. El reto futuro será llegar a los habitantes de las zonas rurales más aisladas, al público femenino y los miembros de las castas consideradas inferiores quienes sufren un mayor grado de analfabetismo y un menor nivel adquisitivo. Todo parecen buenos presagios, el tiempo dirá si se cumplen las expectativas.

\section{Referencias bibliográficas}

GOVERMENT OF INDIA (2001): Ministry of Information and Broadcasting: Annual Report 2000-2001. http://www.mib.nic.in [Fecha de consulta: 2 de octubre 2010]

JEFFREY Robin (2000): Indian's Newspaper Revolution: Capitalism, Politics and the Indian Language Press. New Delhi, Oxford University Press.

JEFFREY Robin (2010): “Communications and Capitalism in India, 1750-2010”. South Asia, pp. 61-75.

KHANNA, Naresh (2002): "Newspaper circulations in India 1998-2000". New Delhi, April. http://www.pressreference.com/Gu-Ku/India.html [Fecha de consulta: 2 de octubre 2010]

NEHRU, Jawaharlal (1982): The Discovery of India, New Delhi, Oxford University Press.

RAGHAVAN G.N.S (1994): The Press in India. A New History. New Delhi Gyan Publishing House.

RAJAGOPAL, Arvind (2001): Politics after Television, Hindu Nationalism and the Reshaping of the Public in India. Cambridge University Press.

RAO N. Bhaskara (1999): “The Newspaper Scene 1998: Miles to Go”. Vidura, January-March, pp. 2. 